Article

\title{
Improvement in Energy Performance of Building Envelope Incorporating Electrochromic Windows (ECWs)
}

\author{
Bo Rang Park ${ }^{1,+}$, Jongin Hong ${ }^{2,+} \oplus$, Eun Ji Choi ${ }^{3}$, Young Jae Choi ${ }^{3}$, Choonyeob Lee ${ }^{4}$ \\ and Jin Woo Moon ${ }^{3, *(D)}$ \\ 1 School of Architecture and Building Science, Chung-Ang University, Seoul 06974, Korea; \\ pbr_1123@naver.com \\ 2 School of Chemistry, Chung-Ang University, Seoul 06974, Korea; hongj@cau.ac.kr \\ 3 School of Architecture and Building Science, Chung-Ang University, Seoul 06974, Korea; \\ ejjchl77@gmail.com (E.J.C.); chlyoungwo@gmail.com (Y.J.C.) \\ 4 Orion Co., Ltd, Gumi-si 39370, Korea; leecy@oriondisplay.net \\ * Correspondence: gilerbert73@cau.ac.kr; Tel.: +82-2-820-5209 \\ + These authors contributed equally to this work.
}

Received: 7 March 2019; Accepted: 23 March 2019; Published: 26 March 2019

\begin{abstract}
The present study sets out to review the thermal and optical properties of electrochromic windows (ECWs) through an analysis of the improvement in the energy performance of a building resulting from their application. The performance analysis was based on the change in the room temperature according to the solar transmittance and the orientation of the ECWs, the energy consumptions of the building's heating/cooling systems, and that of the building's lighting according to the visible light transmittance (VLT). To achieve this, the Quick Energy Simulation Tool (eQUEST), a building energy interpretation program, was used. The solar heat gain coefficient (SHGC) of the ECWs was found to be significantly reduced. This had the effect of lowering the room temperature in summer, such that the effect on the summer cooling energy consumption was also remarkable. However, with a reduction in the VLT, the lighting energy consumption increased. The net result of the changes in the heating/cooling and lighting energy consumptions was a reduction of about $11,207 \mathrm{kWh} / \mathrm{yr}(8.89 \%)$. The ECWs were found to realize a greater reduction in a building's energy consumption than was possible with windows glazed with low-E coated glass.
\end{abstract}

Keywords: electrochromic windows; building energy; smart windows

\section{Introduction}

The amount of energy consumed by buildings constitutes $36 \%$ of total global energy consumption [1]. In Korea, the value is $23.6 \%$ of the country's total energy consumption, with about $77 \%$ of this being consumed for heating and cooling [2]. Gustavsen [3] pointed out that windows have the greatest effect on energy savings because they are responsible for about $60 \%$ of the total energy loss from a building. As such, window performance improvement plays a key role in reducing energy loss and cutting costs. Reilly [4] stated that windows could act as a mediator capable of not only reducing the load on the building but also improving the indoor environment by either allowing or blocking the passing of solar radiation.

Recently, window technologies such as dye-sensitized solar cells, building-integrated photovoltaic panels (BIPV), and solar-control windows as well as high-efficiency window technologies have been developed. However, most of these technologies cannot actually be applied to building envelopes as they cannot simultaneously satisfy the needs for energy saving and visual comfort [5]. To overcome 
these limitations, electrochromic windows (ECWs) have been developed. These control the amount of solar radiation passing through a window without the need for a separate shading device. Instead, the amount of solar radiation relies on a property whereby the transmittance of the glass itself is adjusted. This is not merely a color change but rather an adjustable thermal-barrier effect. As such, ECWs have attracted considerable attention as a new smart-window technology [6].

Studies of the ECWs field are progressing a lot. Investigation of history, state-of-the-art property analysis and installation cases were accomplished to provide sufficient references to the field $[7,8]$. Various simulation performances were conducted to verify the effects of ECWs on building $[9,10]$. Lee et al. conducted a simulation to determine optimal application solution which does not erode energy efficiency and visual comfort. Dussault et al. applied ECWs with a number of design parameters on a representative office building [11]. Also, studies about applying ECWs for energy savings progressed. Lou et al. computed energy reduction of buildings and noted other benefits of ECWs for occupants. Piccolo et al. analyzed optimal performance requirements of ECWs from the perspective of building energy efficiency and indoor comfort. Deb et al. proposed assembly of an photovoltaic powered (PV-EC) device and analyzed compatibility and potential of energy savings for building application [5,12-15]. As a result, the potential of ECWs to realize savings in the energy consumption of a building was identified, with excellent levels of visual environmental satisfaction and significant annual energy savings.

Those ECW-related studies conducted to date have mainly focused on the fabrication and materials. However, few detailed analyses have been conducted that address, for example, the building energy consumption characteristics resulting from the application of ECWs to a building envelope. Therefore, there is a need to determine the thermal and optical properties of a building resulting from the application of ECWs. Given that ECWs can flexibly control the amount of solar radiation passing through them, there is a need to study how they affect the energy performance of a building. Therefore, in the present study, an indoor thermal environment and energy performance evaluation were undertaken to determine how the implementation of ECWs would affect the energy performance of a building. To this end, the performance of a building using ECWs was compared with that of a building using various types of double low-E glazing. The results of any such analysis would be expected to confirm the energy-saving effects of implementing ECWs in future building envelopes, based on their orientation and the schedule devised for their operation.

\section{Introduction of Electrochromic Windows}

\subsection{Overview of Electrochromic Windows (ECWs)}

Chromic materials can reversibly change their optical properties in response to external stimulus, such as light (photochromic materials), temperature (thermochromic materials), and electric potential (electrochromic materials). In particular, the electrochromic materials show the reversible color change between reduction (i.e., gain of electrons) and oxidation (loss of electrons) states [16]. These optical switching materials can regulate the flow of light and heat into and out of window in buildings. This regulation can reduce building energy consumption for heating, ventilation, and air conditioning (HVAC). Electrochromic windows change their transmittance of solar irradiation under the application of electrical voltages, whilst photochromic and thermochromic windows alter their transmittance with the change of light intensity and temperature, respectively. It should be noted that the electrochromic windows provide dynamic modulation of light transmittance in a broad spectral range depending on weather or personal preference or both. In contrast, static glazed windows cannot respond to the change in weather or seasons.

Figure 1 illustrates a typical electrochromic window comprising an active electrochromic layer, a counter electrode layer, an ion-conducting electrolyte between the two electrodes, two transparent conductors and glass substrates $[16,17]$. This structure is referred to as an "electrical thin-film battery" with charging state that translates to a degree of optical absorption. Its essential function results from 
an electrochemical ion intercalation and redox process. In fully colored state, small ions, such as protons $(\mathrm{H}+)$ or lithium ions $(\mathrm{Li}+)$, move from the counter electrode through the electrolyte and they are intercalated into the electrochromic layer (e.g., WO3). In fully bleached state, the ions are extracted from the electrochromic layer and then stored in the counter electrode (e.g., NiO). The light transmittance can be exactly controlled by the amount of inserted ions. This configuration exhibits open circuit memory and thus makes the window be colored for an extended period of time without drawing energy.

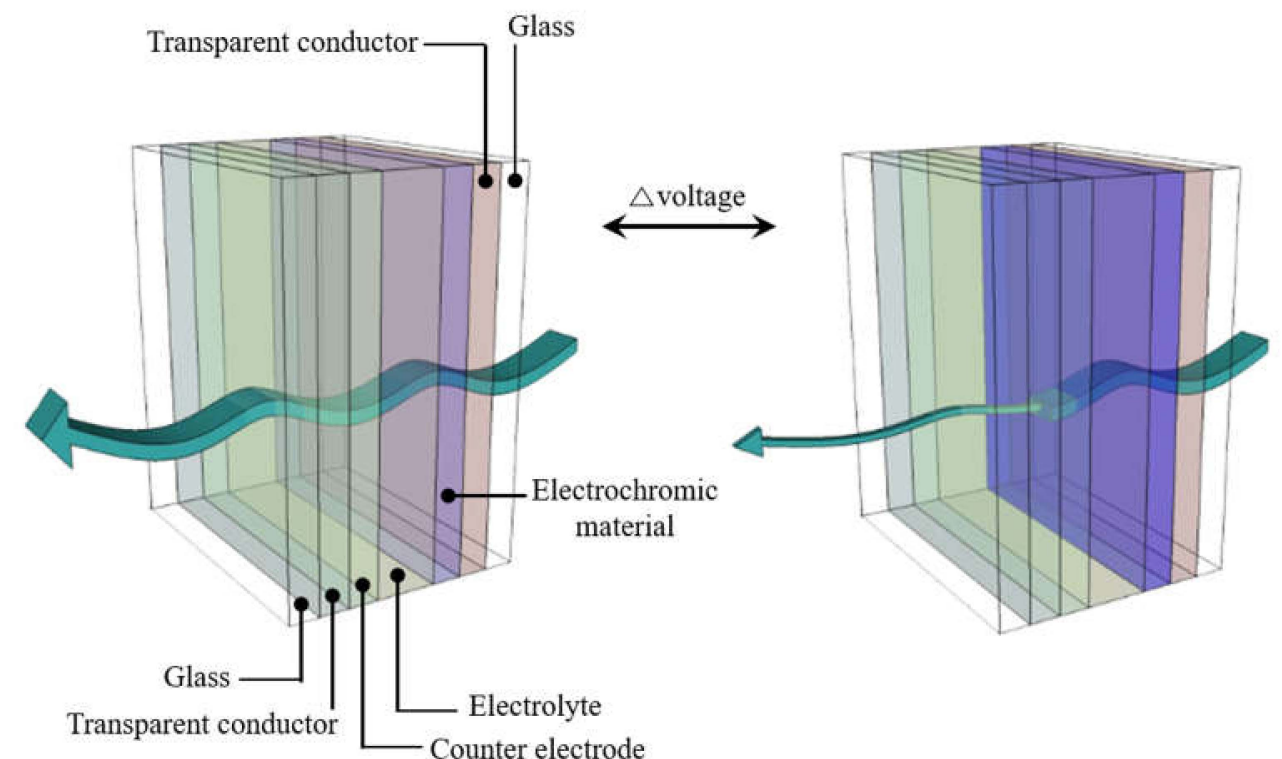

(a) Bleached state

(b) Colored state

Figure 1. A schematic of a typical electrochromic window.

An effective electrochromic window should have fast switching between its "on" and "off" states, a long-term cycle life and a high optical contrast ratio. The switching speed depends on many factors including the electrical conductivity of the transparent conducting materials, the ionic conductivity of the electrolyte, the morphology of the electrochromic layer related to ion intercalation dynamics. Durability is typically assessed by the change in charge capacity or coloration efficiency over thousands of electrochemical cycles. Importantly, coloration efficiency (CE) is considered as a key figure of merit (FoM) to describe the performance of EC devices. The CE is given by [18] where $Q$ is the electronic charge injected into the electrochromic material per unit area, $T_{\text {bleached }}$ is the transmittance in the bleached state, and $T_{\text {colored }}$ is the transmittance in the colored state. Higher coloration efficiency indicates that less charge or energy is needed to achieve larger optical contrast ratio.

$$
\mathrm{CE}(\lambda)=\frac{\Delta O D}{Q}=\frac{\log \left[\frac{T_{\text {bleached }}[\lambda]}{T_{\text {colored }}[\lambda]}\right]}{Q}
$$

Electrochromic windows are highly promising as smart windows, which dynamically control the daylight transmittance into buildings and save building energy consumption. Other switchable smart windows, such as liquid crystal and suspended-particle windows, need constant power to maintain their clear state, although the electrochromic windows only require electricity during switching [19]. However, the electrochromic windows still need to achieve better performance and cost competitiveness for widespread adoption in buildings by more theoretical and experimental investigations on materials and device engineering. 


\subsection{Application of ECWs to Buildings}

The ability of ECWs to control light and heat transmittance could make them extremely advantageous as a building envelope material [20]. As such, they are currently being considered for application as an architectural glass. Table 1 lists actual cases in which ECWs have been used as an architectural glass [21]. To date, they have mainly been applied as outer windows and skylights in multi-purpose buildings. They have not only reduced the cooling loads of those buildings, but have also created a pleasant internal environment through their ability to change color. However, the investigated cases are applied, the ECWs was applied to the entire building envelope in en bloc, so that effective energy saving suitable for the characteristics of each building has not been achieved. In order to solve this problem, the energy performance analysis of various ability of ECWs will be carried out and it is expected to contribute to the application plan of ECWs in accordance with the building-specific requirements of the future.

Table 1. Case study of electrochromic window (ECW) buildings.

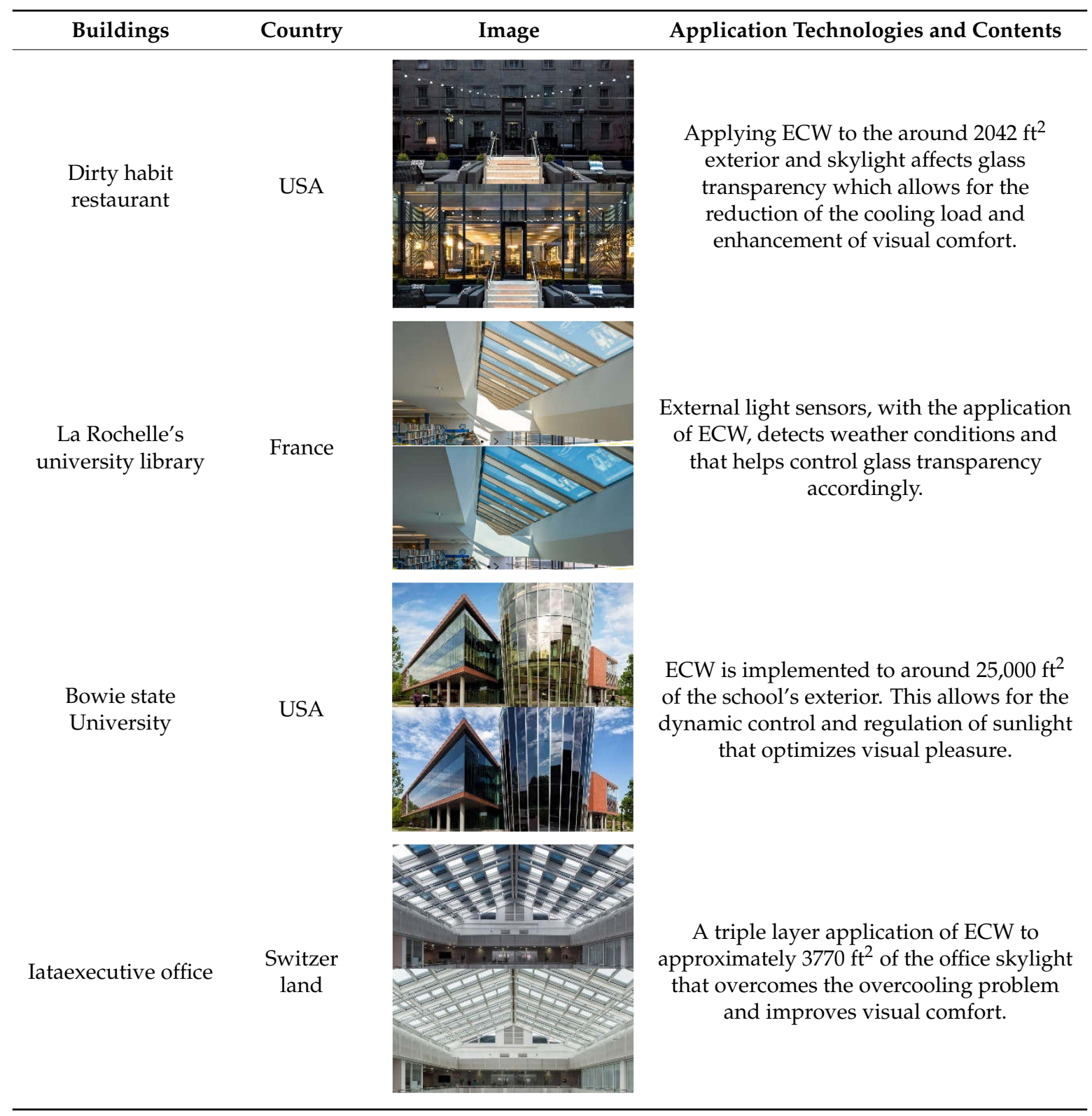


Table 1. Cont.

\begin{tabular}{|c|c|c|c|}
\hline Buildings & Country & Image & Application Technologies and Contents \\
\hline Ashford castle & Ireland & & $\begin{array}{l}\text { ECW is applied to the exterior in a } \\
\text { remodeling process to a hotel building } \\
\text { complete before } 1228.99 \% \text { of visible light } \\
\text { can be cut off in the darkest condition of } \\
\text { Summer, and maximum solar radiation is } \\
\text { obtainable during the Winter. }\end{array}$ \\
\hline Government center & Netherlands & & $\begin{array}{l}\text { Application of ECW to the skylight of a } \\
\text { meeting room utilized optimum solar } \\
\text { radiation that reduces glare, cooling loads, } \\
\text { and blocks up to } 98 \% \text { of maximum solar } \\
\text { radiation. }\end{array}$ \\
\hline New Babylon & Netherlands & & $\begin{array}{c}\text { Displaying images via the combination of } \\
\text { LEDs and ECWs which } 82 \% \text { transparency } \\
\text { on the exterior of the building, light } \\
\text { pollution and energy consumption is } \\
\text { reduced by } 30 \% \text {. }\end{array}$ \\
\hline $\begin{array}{l}\text { Omicron head } \\
\text { office }\end{array}$ & Austria & & $\begin{array}{l}510 \text { ECW-applied glass modules and } 90 \\
\text { LED glass panels of the building's exterior } \\
\text { saves } 66,000 \mathrm{kWh} \text { annually. }\end{array}$ \\
\hline
\end{tabular}

\section{Evaluation}

\section{Simulation Model}

In this present study, the ECW performance was analyzed based on the following three points:

- Change in room temperature with the amount of solar radiation being allowed into the room,

- For given orientations

- Seasonal building energy consumption, and peak-day energy consumption

- Lighting energy consumption

The above are the three main factors affecting window applications. First, the shading coefficient (SC) indicates the degree to which the solar radiation transmittance is blocked, and therefore determines the amount of solar energy reaching the interior of a building. A low SC causes the cooling energy consumption to be reduced in the summer, but the heating energy consumption will increase in the winter. In addition, as the solar transmission directly affects the room temperature and, therefore, the operation of the heating and cooling systems, it must be closely monitored. Second, to determine a building's energy consumption, the heating and cooling energy was analyzed by season, and the peak-day energy consumption was further analyzed to determine the building's energy consumption during stable operation. Third, visible light transmission (VLT) was selected for analysis, given that it is not only an important factor determining the visual environment comfort, but also affects the 
indoor lighting and the amount of internal load from the artificial lighting systems which also affects the heating and cooling energy consumption.

To analyze the performance, eQUEST, a US Department of Energy (DOE) dynamic energy interpretation program, was used. The eQUEST program is a building energy analysis program that uses the DOE-2 engine. This is a Windows-compatible product with a graphical input method, which makes processing easier. It can identify and analyze the monthly and annual energy consumption, the load by element, as well as the peak load, based on data such as the regional climate data, building modeling and the insulation performance of the structure, the building use schedule, indoor set temperature, heating method and lighting, and electrical capacity [22].

The simulation target buildings were standard office buildings of a typical size and shape in Seoul, Korea. Table 2 lists the physical indices and operation settings. The thermal transmittance was set according to the energy-saving design standards. For the heating/cooling system, a DX coil provided by the eQUEST program, suitable for the target building, was selected. In addition, the standard meteorological data for the Seoul area for one year was utilized.

Table 2. Parameters of simulation model.

\begin{tabular}{ccc}
\hline $\begin{array}{c}\text { Target Building } \\
\text { Components }\end{array}$ & \\
\hline Modeling & & \\
& & \\
& & \\
Location & Seoul, Republic of Korea (Latitude: $37.5^{\circ} \mathrm{N}$, Longitude: $\left.127.1^{\circ} \mathrm{E}\right)$ \\
Weather & Year & 2018 \\
& Building Size & $5 \mathrm{~F}$ \\
Area and Other data & Number of Floors & No \\
& Daylighting control & Rectangle \\
& Footprint Shape & Perimeter $/$ core \\
Building Footprint & Zoning Pattern & South \\
& Building Orientation & $3.8 \mathrm{~m}$ \\
& Floor Heights (Flr-To-Flr) & $6.67 \mathrm{~m}^{2} \mathrm{~K} / \mathrm{W}$ \\
Building & Roof surface(R-value) & $4.17 \mathrm{~m}^{2} / \mathrm{W}$ \\
Envelopeconstructions & Above grade wall (R-value) & $5.00 \mathrm{~m}^{2} / \mathrm{W}$ \\
\hline
\end{tabular}

The four types of window used in the present study are listed in Table 3. Three types of double low-E glazing, frequently used in modern buildings, were selected as a comparison group to evaluate the performance of the ECWs. The three types of window in the comparison group all have transparent low-E glass and an air (or argon gas) layer, configured as a double-layered structure. The different types are classified based on the location of the surface with the Low-E coating. Among these, C-2 (with the low-E coating on the inner glass) was set as the reference case. 
Table 3. Physical properties of exterior window.

\begin{tabular}{|c|c|c|c|c|c|c|c|c|}
\hline \multicolumn{2}{|c|}{ Type } & $\begin{array}{l}\text { Low-E } \\
\text { Coating } \\
\text { Face }\end{array}$ & $\begin{array}{l}\text { Glazing Layer } \\
\text { [No. Thickness] }\end{array}$ & $\begin{array}{l}\text { U-Value } \\
{\left[\mathrm{W} / \mathbf{m}^{2} \mathbf{K}\right]}\end{array}$ & SHGC & sC & VLT & Note \\
\hline \multicolumn{2}{|c|}{ C-1 } & 2 & Low-e $6+\operatorname{Ar} 12.7+\mathrm{Clr} 6$ & 1.36 & 0.58 & 0.67 & 0.74 & \\
\hline \multicolumn{2}{|c|}{$\mathrm{C}-2$} & 3 & Clr $6+\operatorname{Ar} 12.7$ + Low-e 6 & 1.36 & 0.61 & 0.71 & 0.74 & Base \\
\hline \multicolumn{2}{|c|}{$\mathrm{C}-3$} & 2,3 & Low-e 6 + Ar 12.7 + Low-e 6 & 1.23 & 0.50 & 0.58 & 0.71 & \\
\hline & ECC & 3 & EC (Colored) $6+\operatorname{Ar} 12.7$ + Low-e 6 & 1.27 & 0.12 & 0.14 & 0.10 & \\
\hline ECW & ECB & 3 & EC (Bleached) 6+ Ar $12.7+$ Low-e 6 & 1.27 & 0.52 & 0.60 & 0.66 & \\
\hline
\end{tabular}

*SHGC: Solar Heat Gain Coefficient, SC: Shading Coefficient, VLT: Visual Light Transmission.

An ECW is configured with electrochromic glass $(6 \mathrm{~mm})$, a $12.7 \mathrm{~mm}$ air (or argon) layer, and 6-mm low-E coated glass (coated on three sides) in a double-layer structure, and for the thermal and optical properties of each glass, the values listed for 'Double Low-E (e2 = 0.029) Electrochromic Absorbing Bleached (2844)/Colored(2845)' according to the operation (ECC) and non-operation (ECB) conditions of the ECW, using the physical properties data listed in The DOE-2.2 Volume 4: Libraries and Reports. Solar heat gain coefficient (SHGC) of ECB is 0.52 and when it is colored, it turns to 0.12 (ECC). Along with, shading coefficient (SC) changes from 0.60 to 0.14 and visible transmittance (VT) turn to 0.10 from 0.66 . The detail properties are defined in Table 3. Modeling was performed by establishing zones with the perimeter space and planum for the three criteria of ground, mid, and top by orientation, to identify the solar transmittance and indoor temperature according to the application orientation and window type.

The operation schedule for the ECWs was set as defined in Table 4. For the general windows, the thermal and optical schedules are constant. For an ECW, however, given that its characteristics can be controlled to suit the time and external environment, the control method can be an important strategy in determining the energy performance of a building. Given the nature of the energy consumption of an office building, the ECW operation schedule was set by considering the high summer cooling load. The winter season was set to January/February and November/December. During this season, the ECWs were not operated. However, from March to May and in October, when large amounts of solar radiation would enter the building, the ECWs were set to become colored from 11:00 to 15:00. During the summer (June-September), the coloration was set to occur between 08:00 and 18:00, matching the occupancy of a typical office building. The electrical energy consumption required to switch the ECWs $0.05 \mathrm{Wh} / \mathrm{m}^{2}$ respectively at the colored or bleached operations based per one day.

Table 4. ECW colored schedule.

\begin{tabular}{cc}
\hline Month & Colored Time \\
\hline 1 January 2018-28 February 2018 & - \\
1 March 2018-31 May 2018 & 11:00 15:00 \\
1 Jun 2018-30 September 2018 & $08: 00 \sim 18: 00$ \\
1 October 2018-31 October 2018 & 11:00 15:00 \\
1 November 2018-31 December 2018 & - \\
\hline
\end{tabular}

\section{Result and Analysis}

\subsection{Solar Radiation Transmittance and Indoor Temperature}

The change in the indoor temperature with the solar transmittance, and the effect of the ECW installation, were analyzed. The heating and cooling systems were turned off only to analyze how the indoor temperature was affected by the solar radiation transmittance. The change in the monthly average solar transmittance and indoor temperature with the ECWs, relative to the reference window type (C-2) are shown in Figures 2-10. 


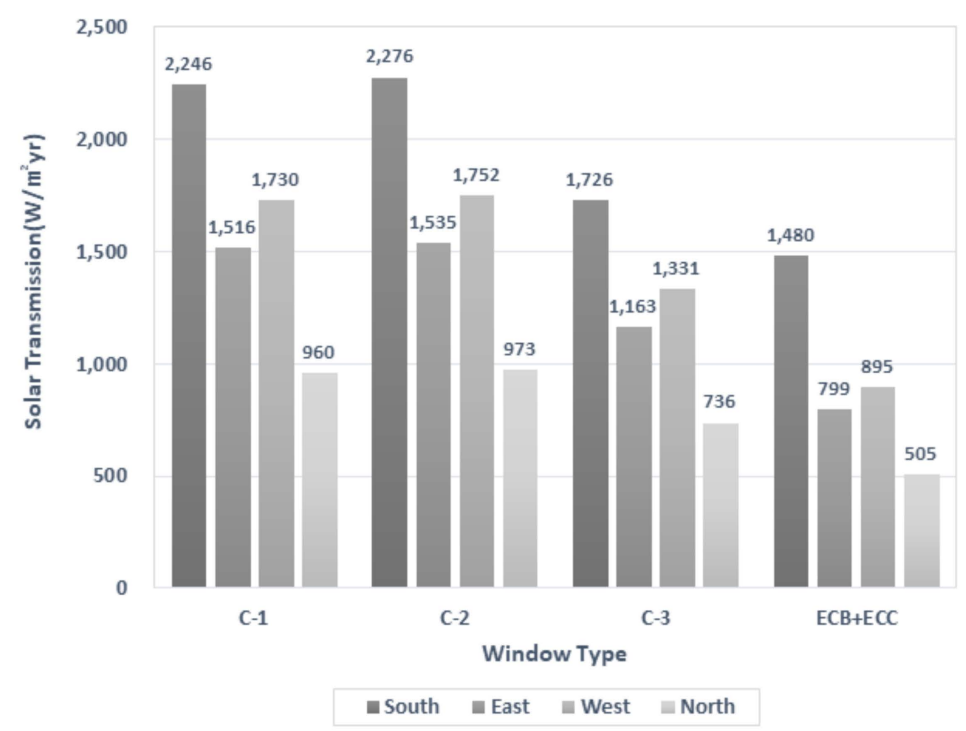

Figure 2. Annual solar transmission rate by orientation according to window type.

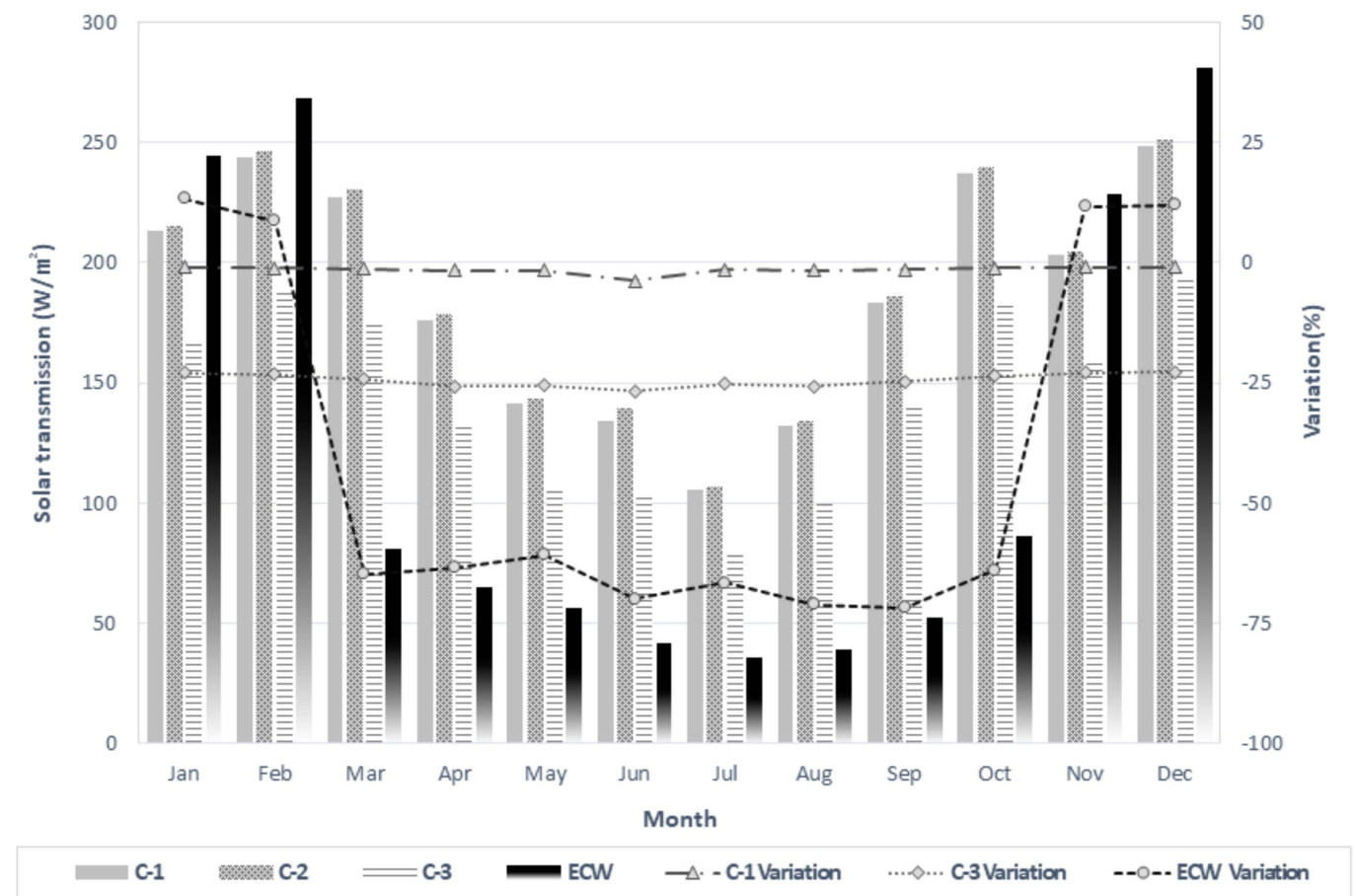

Figure 3. Solar transmission performance by direction (Monthly)—South. (Variation: A percentage change compared to base model(C-2)). 

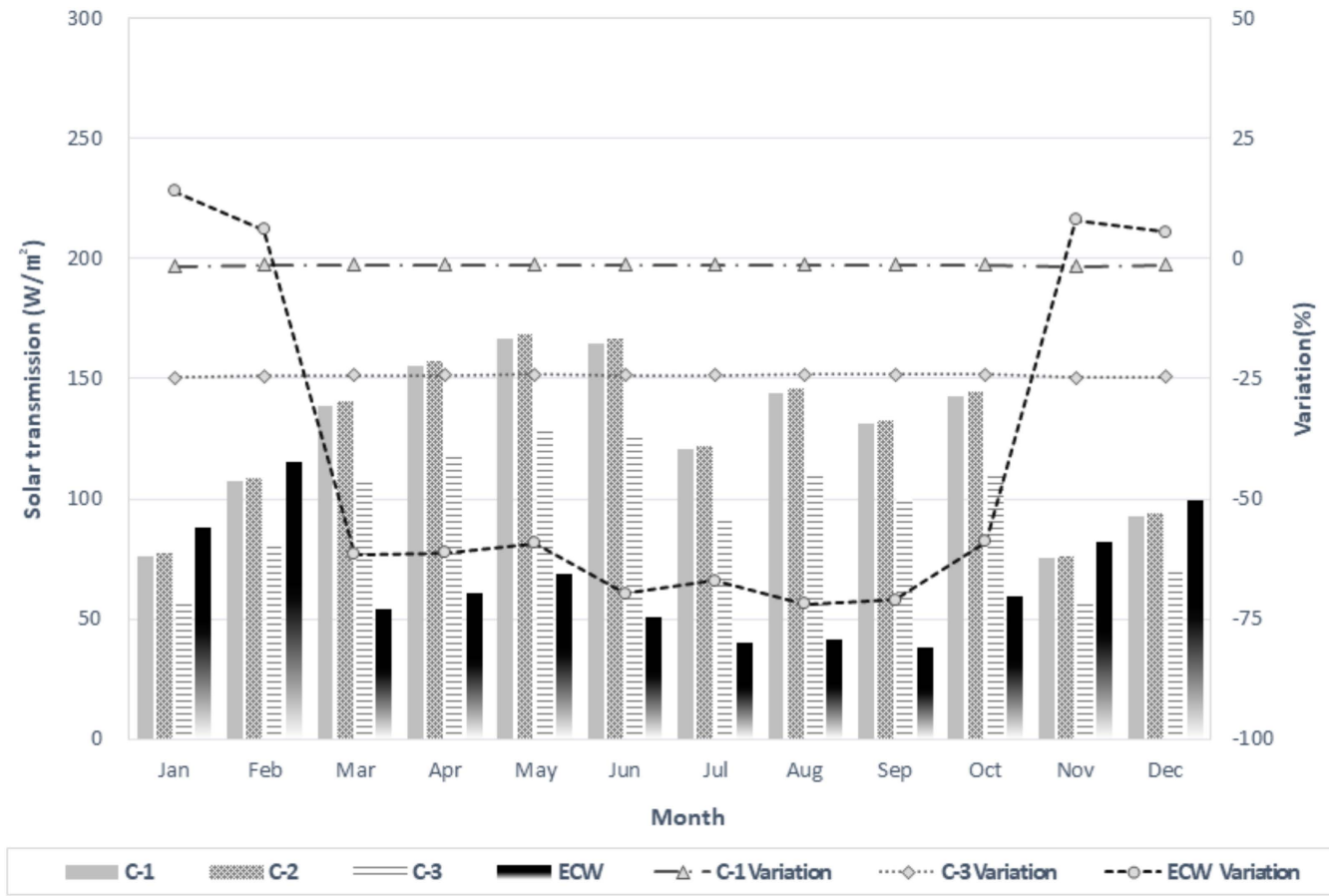

Figure 4. Solar transmission performance by direction (Monthly)—East.

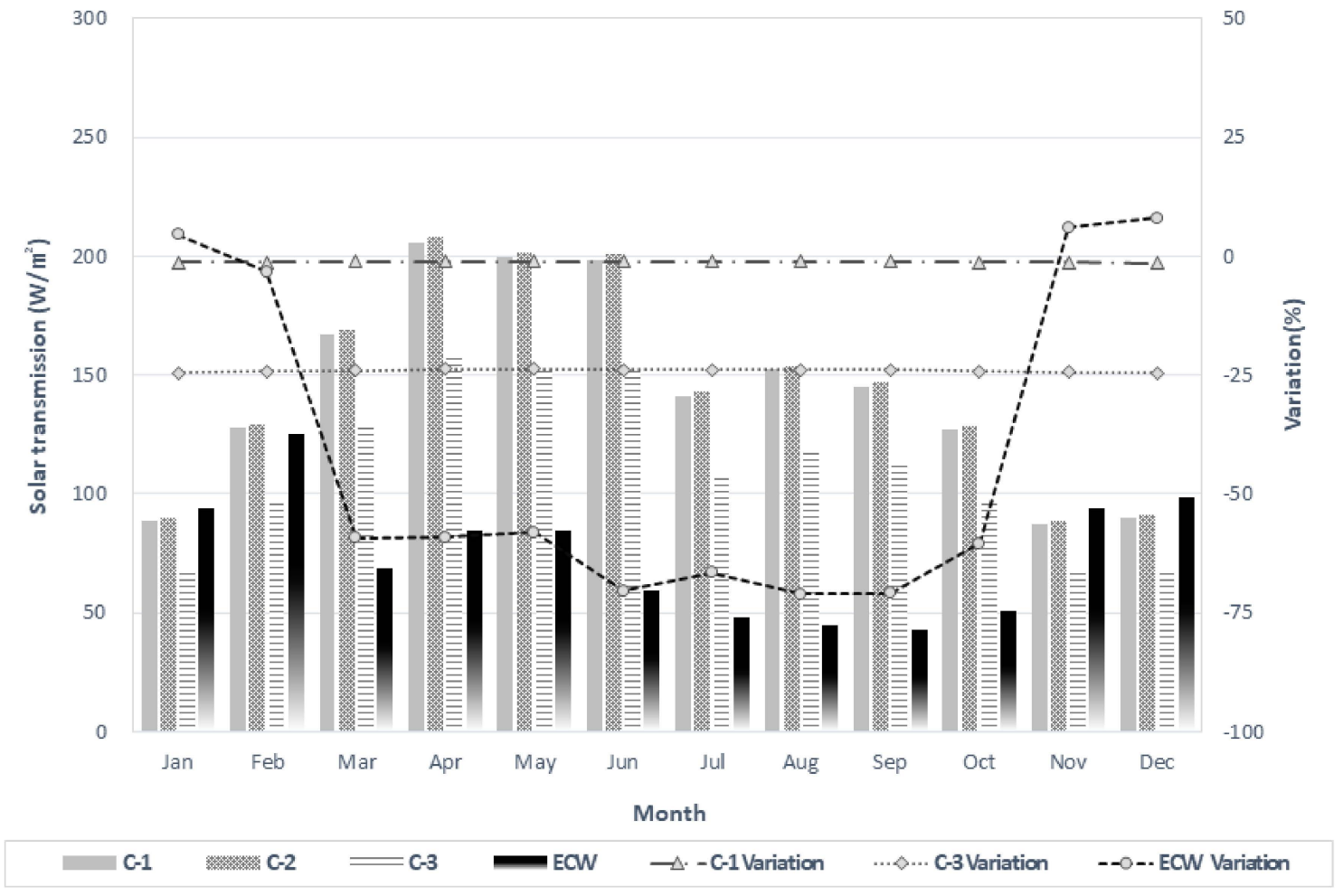

Figure 5. Solar transmission performance by direction (Monthly)—West. 

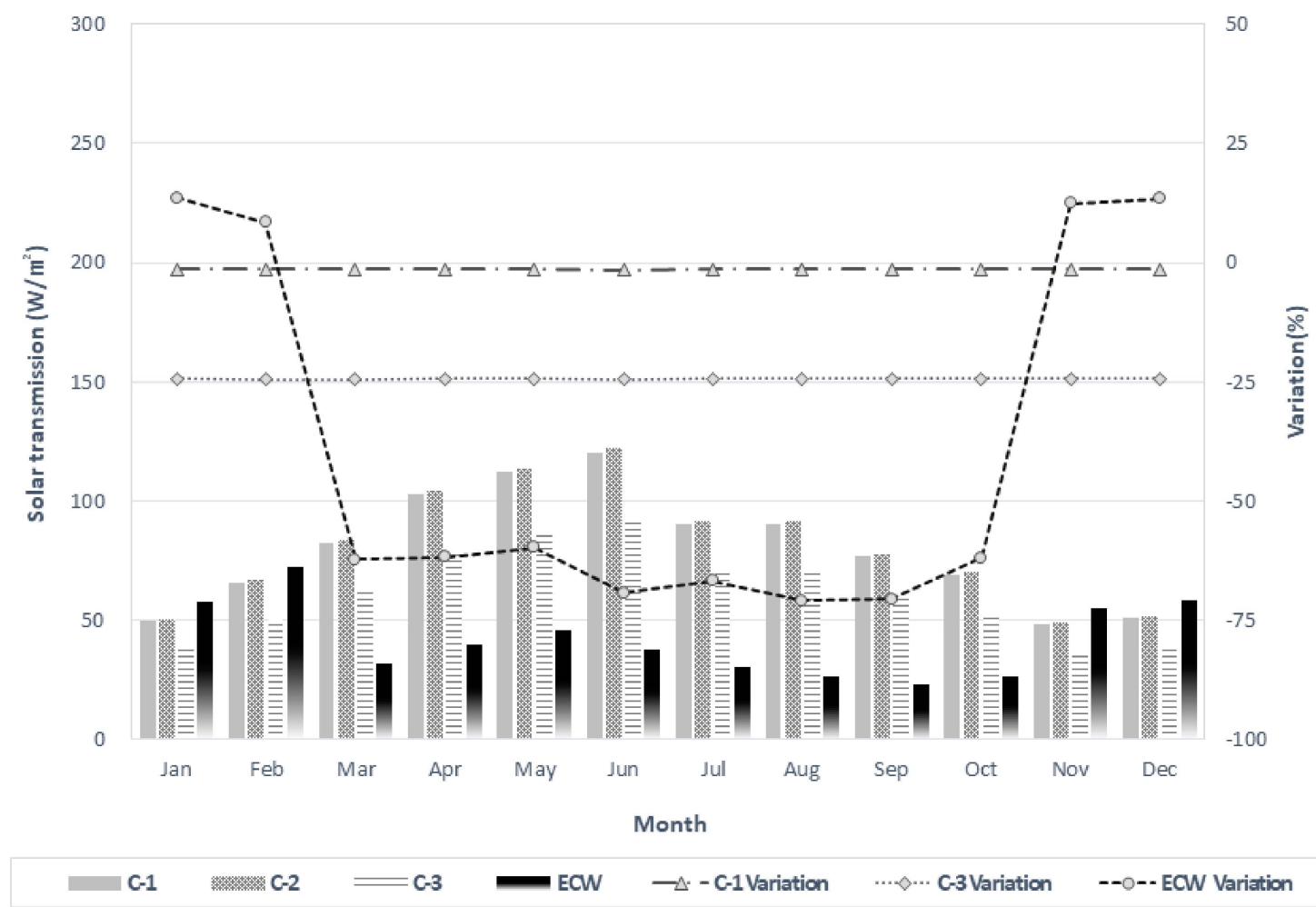

Figure 6. Solar transmission performance by direction (Monthly)—North.

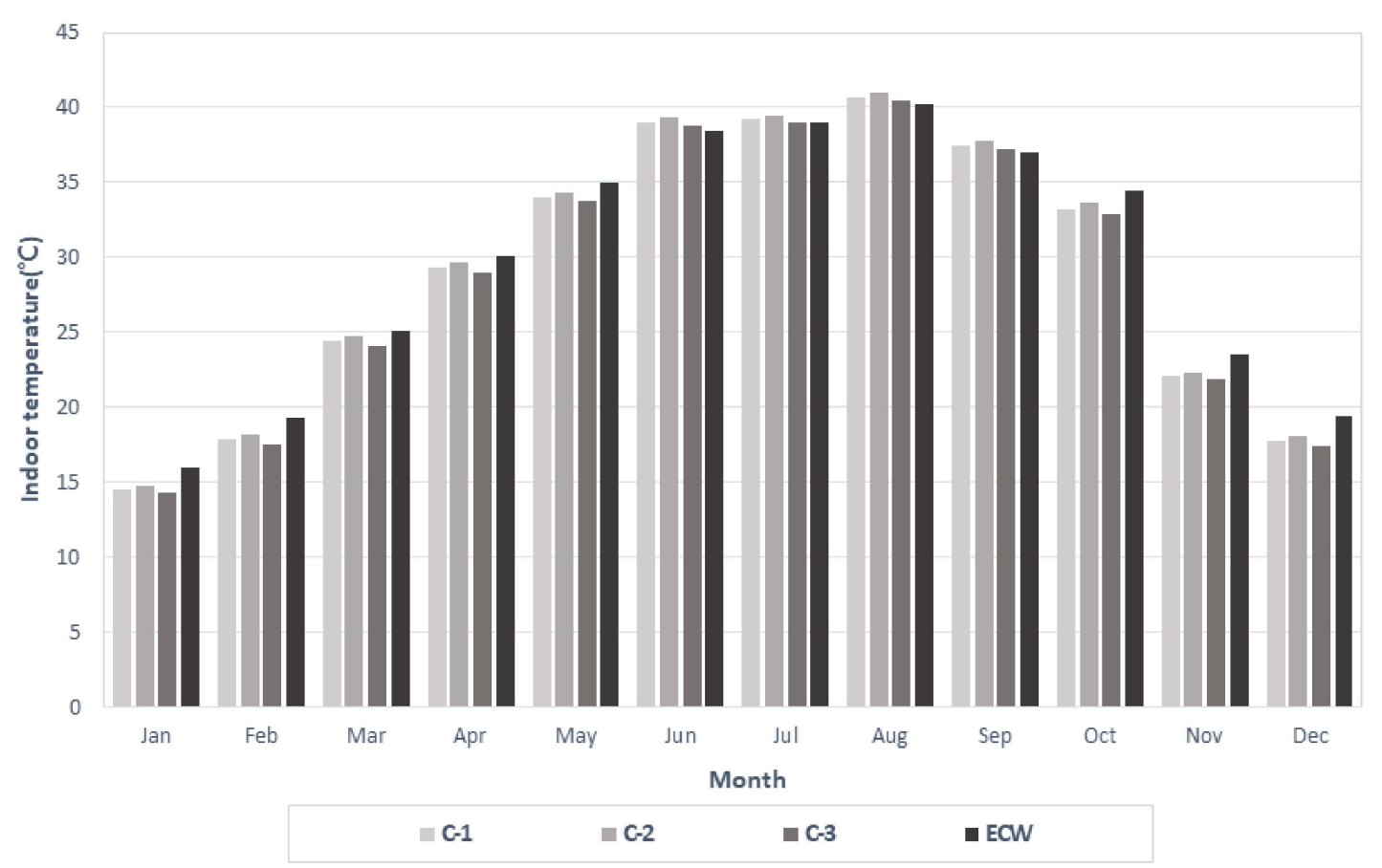

Figure 7. Indoor temperature by direction (Monthly)—South. 


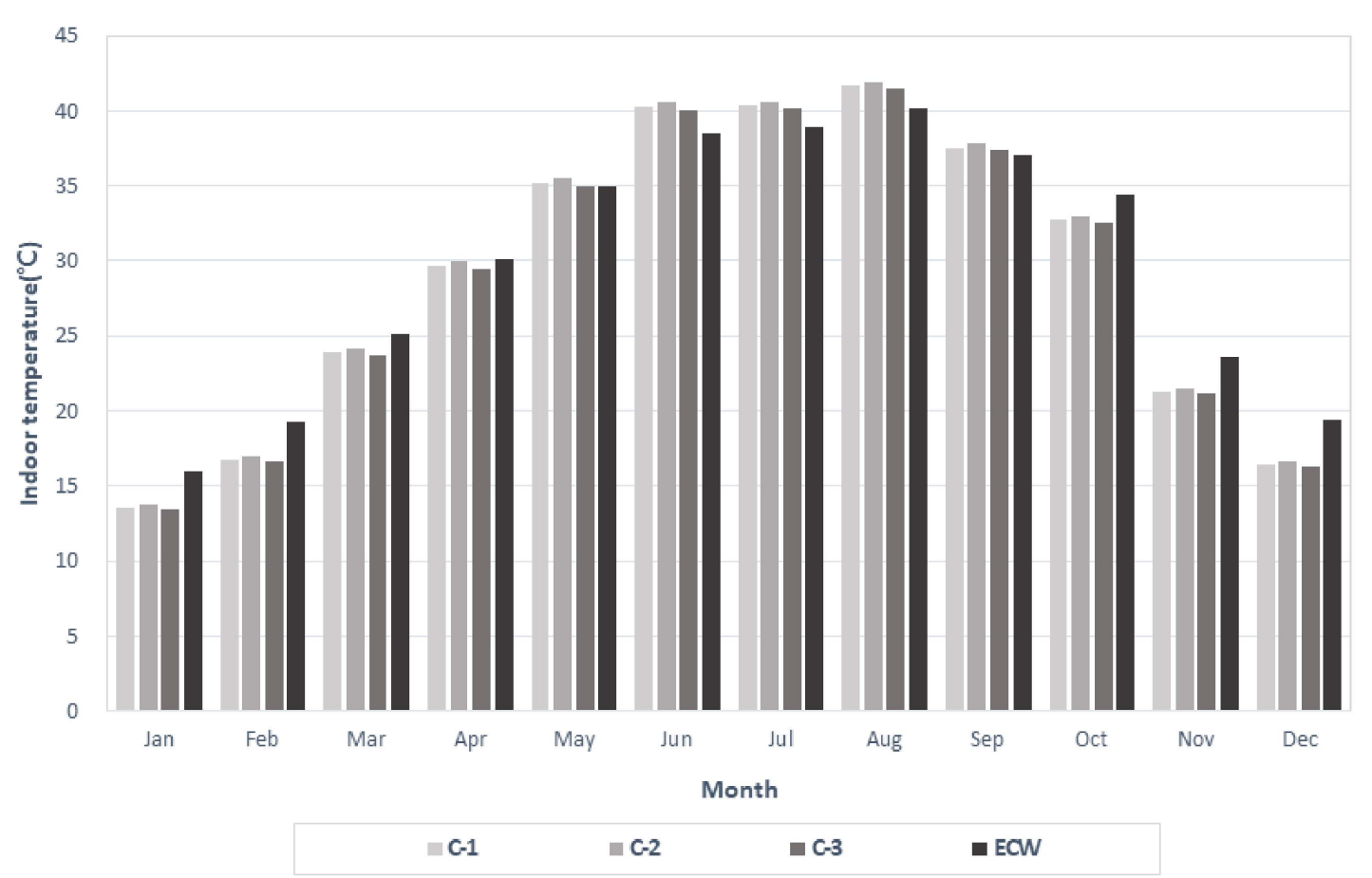

Figure 8. Indoor temperature by direction (Monthly)—East.

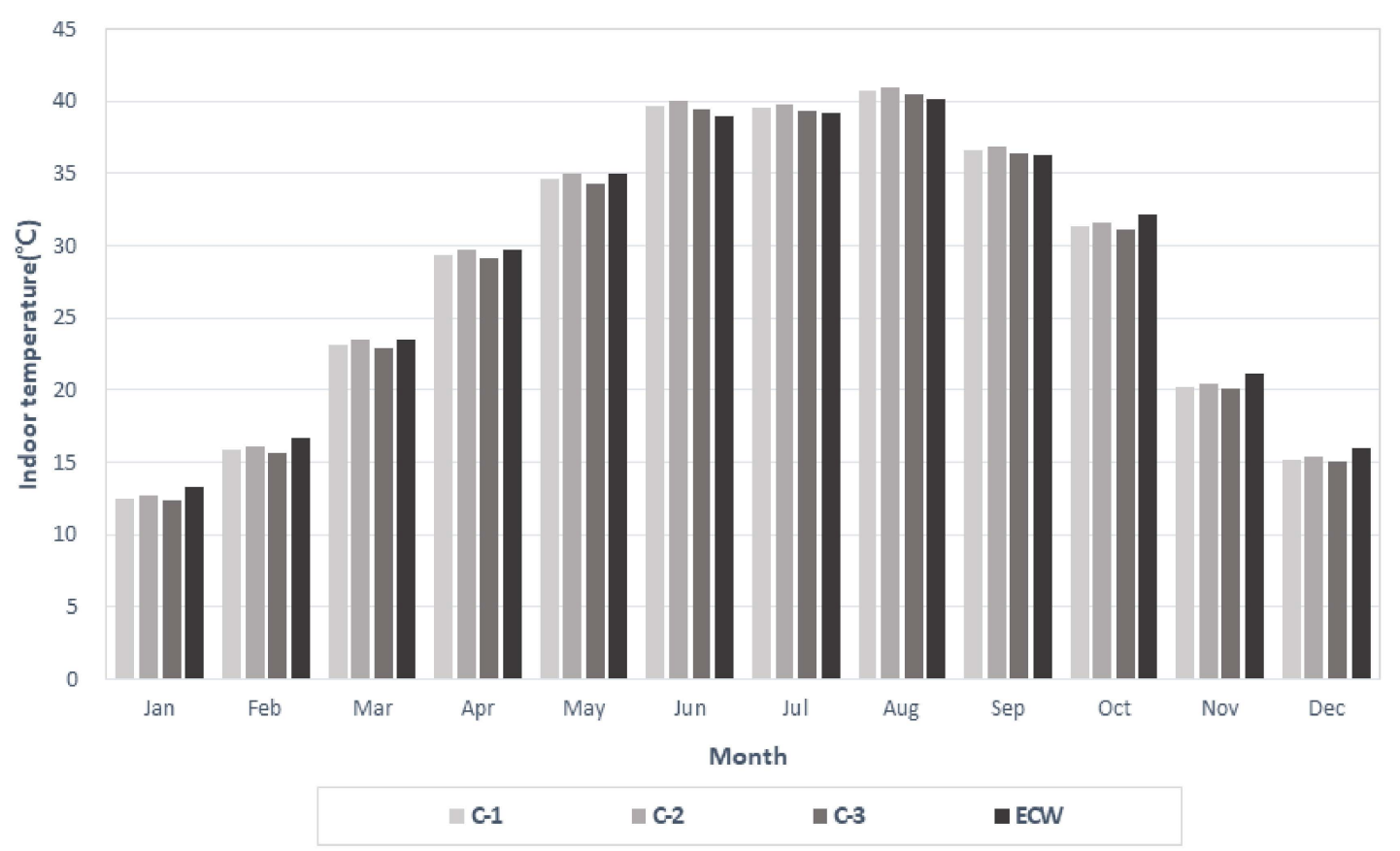

Figure 9. Indoor temperature by direction (Monthly) —West. 


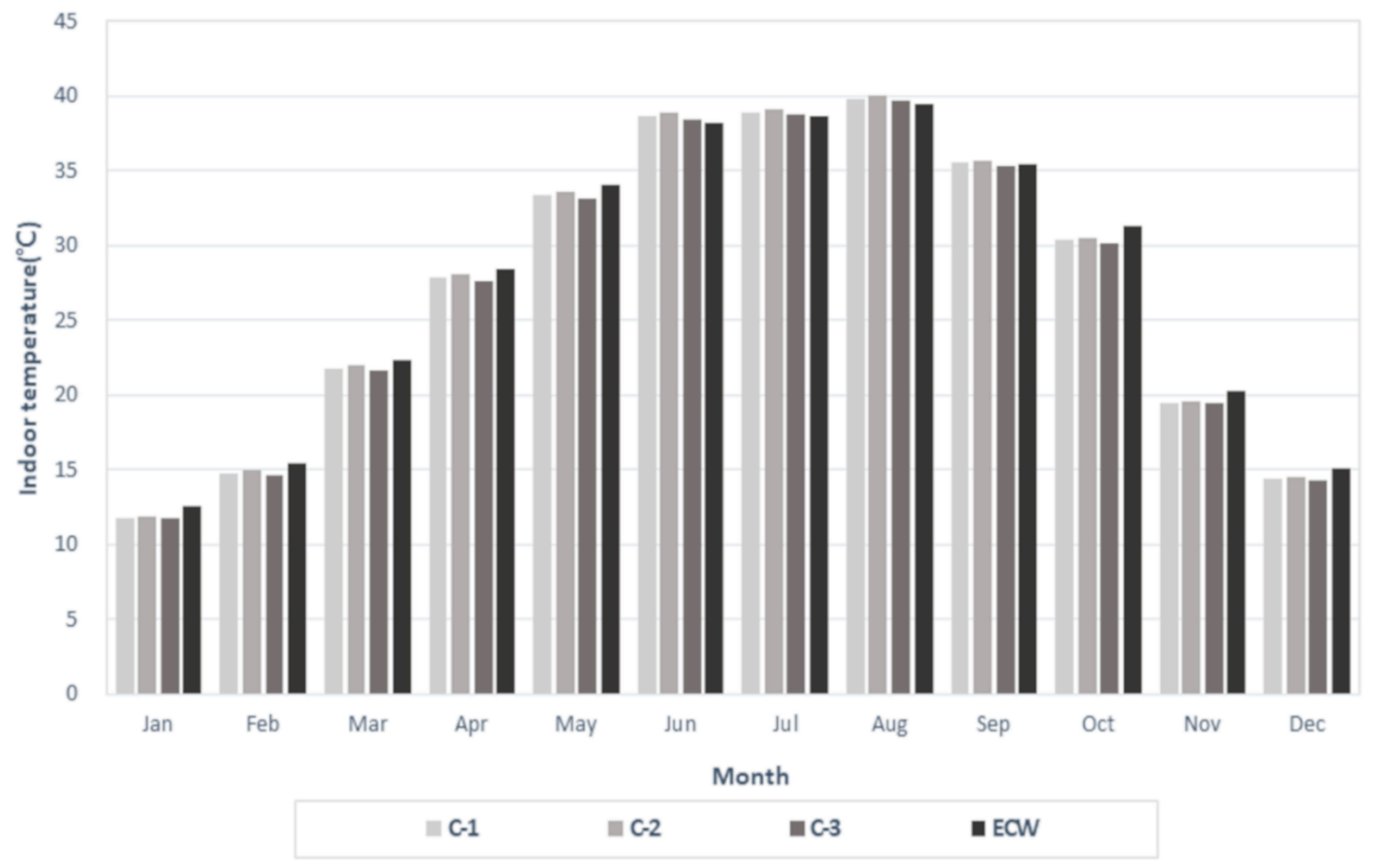

Figure 10. Indoor temperature by direction (Monthly) - North.

Figure 2 shows the annual solar transmittance according to the orientation of the window. For every window type, it was found that the transmittance decreased in the order of south-west-east-north. Regardless of the orientation, the highest transmittance for the reference model(C-2) was $6536 \mathrm{~W} / \mathrm{m}^{2}$, while that for the ECW was $3679 \mathrm{~W} / \mathrm{m}^{2}$, it showed the lowest value as $2857 \mathrm{~W} / \mathrm{m}^{2}(0.44 \%)$ compared to the reference model. In addition, ECW is the highest in winter and the lowest in summer, showing the highest cooling and heating energy reduction rate in all orientation than the $C$ type windows.

The highest solar transmittance was recorded for the southerly orientation, while the lowest was for the northerly orientation, which is assumed to be a common characteristic of buildings in the northern hemisphere. The easterly and westerly orientations exhibit a similar phenomenon, with the westerly orientation being higher at $695 \mathrm{~W} / \mathrm{m}^{2}(13.86 \%)$ than easterly. This is thought to be due to the longer solar radiation transmittance time during the afternoon.

Considering the values obtained for the solar transmittance according to window type and orientation, Figure 3 shows that for a window oriented towards to the south. In this orientation, the ECWs attained the highest solar transmission $\left(1022.56 \mathrm{~W} / \mathrm{m}^{2}\right)$ in winter, corresponding to an increase of $104.45 \mathrm{~W} / \mathrm{m}^{2}(11.38 \%)$ relative to the reference model $\left(918.11 \mathrm{~W} / \mathrm{m}^{2}\right)$. These characteristics are assumed to be a result of the large SC value as the ECWs are in their bleached state throughout the winter. On the other hand, in the mid-periods and summer, the solar transmission was $288.62 \mathrm{~W} / \mathrm{m}^{2}$ and $76.40 \mathrm{~W} / \mathrm{m}^{2}$, that is reductions of $503.75 \mathrm{~W} / \mathrm{m}^{2}(63.58 \%)$ and $489.40 \mathrm{~W} / \mathrm{m}^{2}(86.50 \%)$, respectively, relative to the reference model.

The solar transmittance results for those windows oriented towards the east and west are shown in Figures 4 and 5. The annual solar transmittance of east and west orientations are identified as the similar values, for the reference model in the mid-periods, the easterly and westerly orientations have the highest transmittances of $610.98 \mathrm{~W} / \mathrm{m}^{2}$ and $707.40 \mathrm{~W} / \mathrm{m}^{2}$, respectively, and the ECW had the lowest by the decrease compared to reference model as $488.33 \mathrm{~W} / \mathrm{m}^{2}(79.93 \%)$ for east orientation and $418.17 \mathrm{~W} / \mathrm{m}^{2}(59.11 \%)$ for west orientation. Figure 6 shows that the reference model has the highest like other orientations as a result of north orientation, and the ECW has the lowest. The reference model compared to south orientation has the lower by $1286 \mathrm{~W} / \mathrm{m}^{2}(57.26 \%)$ annually, and the ECW 
was lower at $975 \mathrm{~W} / \mathrm{m}^{2}(65.88 \%)$. The results of this analysis, the effects of heating energy reduction of buildings in winter and cooling energy reduction in summer can be expected by adjusting the seasonal solar transmittance through the application and proper operation of the ECW.

Figures 7-10 show the indoor temperature change according to the solar radiation transmittance of a window and the orientation. The analysis of the indoor temperature reflected the different characteristics of the three types in the comparison group, according to the location of the low-E coating. Solar radiation is reflected outwards if the low-E coating is on the outer surface. When the coating is on the inner surface, however, the solar radiation is reflected outwards, while any heat generated inside is reflected into the building. The changes in the indoor temperature in southerly oriented are shown in Figure 7. For the ECWs in south orientation, the average indoor temperature (June-September) was lowest at $38.38^{\circ} \mathrm{C}$, which is $0.99{ }^{\circ} \mathrm{C}$ lower than that with the reference model. For the average indoor temperature in summer (June-September) in south orientation, the ECWs showed the lowest as $38.38^{\circ} \mathrm{C}$, which is reduced by $0.99^{\circ} \mathrm{C}$ compared to the reference model, and while for the average in winter (January/ February, November/December), the ECW showed the highest among windows as $19.55{ }^{\circ} \mathrm{C}$, which is increased by $1.20^{\circ} \mathrm{C}$ higher than that with the reference model. During the mid-periods, the ECWs produced an average indoor temperature that was $0.54{ }^{\circ} \mathrm{C}$ higher than that attained with the reference model. It was thus possible to confirm how the ECW increased/decreased the solar transmittance in winter. Windows C-1 and C-2 produced decreases relative to the reference model, regardless of the season.

Figure 8 shows the indoor temperature change in the east orientation. The indoor temperature with the reference model was $40.23^{\circ} \mathrm{C}$ in summer, which was higher than that attained with the other windows, while that with the ECW was lowest at $39.36^{\circ} \mathrm{C}$, a decrease of $0.87^{\circ} \mathrm{C}$ compared to the reference model. C-1 and C-2 also produced a decrease. In the winter, the ECW produced the highest indoor temperature at $17.82{ }^{\circ} \mathrm{C}$, unlike in the summer, when the change in the indoor temperature, relative to the C-type reference model, was the same as that for a southerly oriented window, being $0.62{ }^{\circ} \mathrm{C}$ higher.

Figures 9 and 10 indicate the indoor temperature with windows oriented towards the west and north. For both orientations, the ECW produced the highest indoor temperatures, at $16.79{ }^{\circ} \mathrm{C}$ for the westerly orientation in winter and $15.85{ }^{\circ} \mathrm{C}$ for the northerly orientation. In the summer, the indoor temperatures were lowest at $38.61{ }^{\circ} \mathrm{C}$ for the westerly orientation and $37.90{ }^{\circ} \mathrm{C}$ for the northerly orientation.

\subsection{Annual and Peak Day Heating/Cooling Energy}

To analyze the effect of the window type on a building's energy consumption, a seasonal heating/cooling analysis and a peak energy analysis for each of the heating and cooling were performed. For the ECWs, $0.05 \mathrm{Wh} / \mathrm{m}^{2}$ of electrical energy was assumed to be required for the coloring/bleaching operations. These operations were assumed to be performed twice a day.

Table 5 and Figure 11 show the annual energy consumption by season. In terms of the total annual energy consumption, the value was highest with the reference model at 125,490 kWh/yr, with cooling consuming more energy than heating. The energy consumption fell in the order of C-1-C-3 ECWs, with the ECW attaining the greatest reduction at $10,578 \mathrm{kWh} / \mathrm{yr}(8.43 \%)$, relative to the reference model. This is assumed to be a result of the reduction in heat loss in the winter, as well as a reduction in the solar radiation transmittance in summer, given the ECW U-value and the solar radiation transmittance. 
Table 5. Annual energy consumption by season.

\begin{tabular}{ccccc}
\hline \multirow{2}{*}{ Type } & \multicolumn{3}{c}{ Amount of Energy [kWh/yr] } \\
\cline { 2 - 5 } & Heating & \multicolumn{2}{c}{ Cooling } & Total \\
\cline { 2 - 5 } & Winter & Summer & Intermediate & Entire \\
\hline C-1 & 48,920 & 63,060 & 12,240 & 124,220 \\
C-2 & 48,270 & 64,490 & 12,730 & 125,490 \\
C-3 & 49,200 & 61,510 & 11,720 & 122,430 \\
ECWs & 47,870 & 56,082 & 10,960 & 114,912 \\
\hline
\end{tabular}

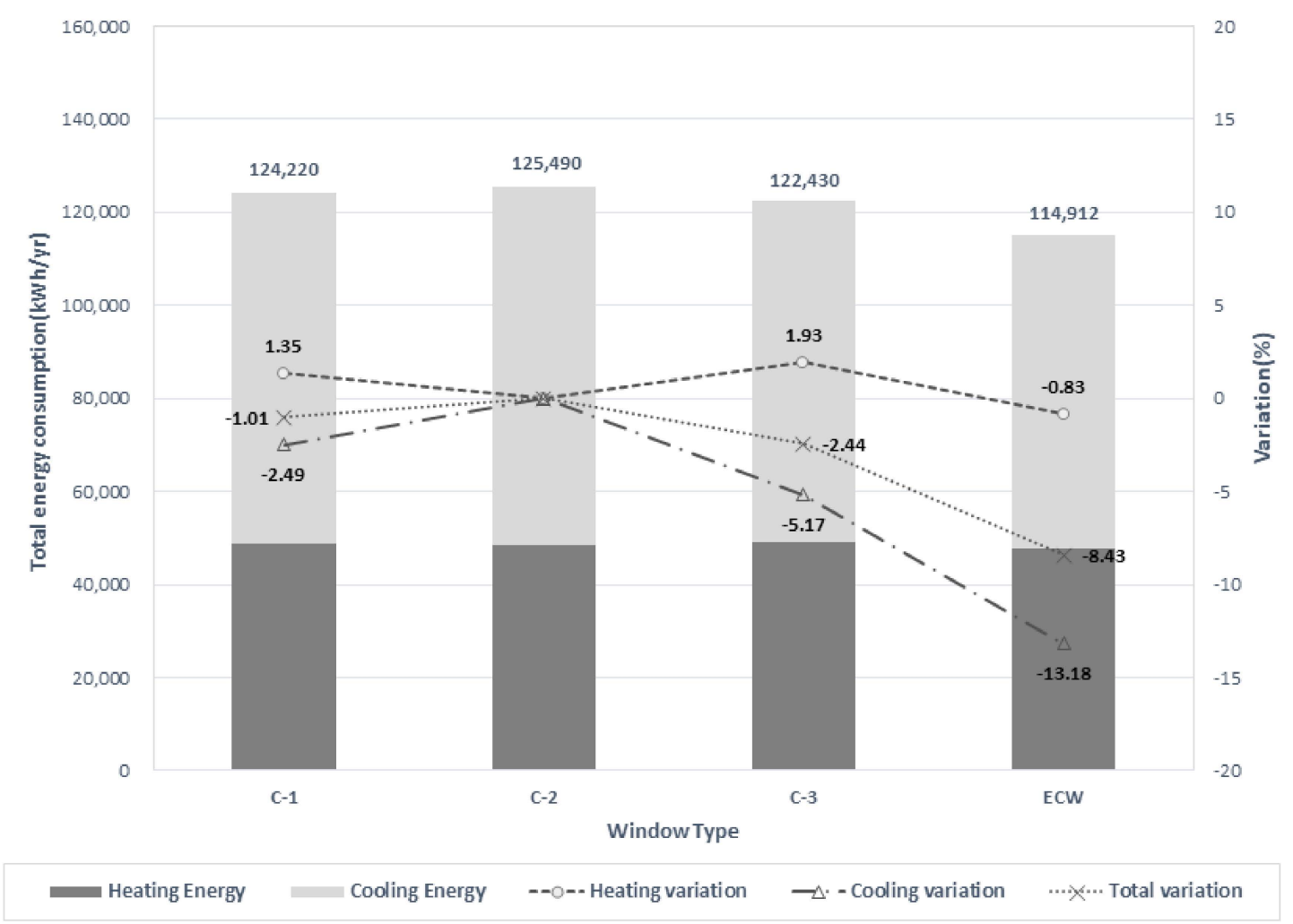

Figure 11. Annual heating and cooling energy consumption. (Variation: A percentage change compared to base model(C-2)).

In winter (January/February, November/December) the energy consumption with the ECWs was the lowest of all the window types, at $56,082 \mathrm{kWh} / \mathrm{yr}$ which was $7812 \mathrm{kWh} / \mathrm{yr}(0.83 \%)$ less than that with the reference model. Given that the ECW is set to the bleached state in winter, while the thermal transmittance is low, it reduces heat loss in the winter, when the nights are longer than in summer. In the summer (June-September) and the mid-periods (March-May, October), the cooling energy consumption with all the windows was lower than that with the reference model, with the reduction with the ECW being the greatest at $8408 \mathrm{kWh} / \mathrm{yr}(13.04 \%)$ in summer and $1770 \mathrm{kWh} / \mathrm{yr}$ $(13.91 \%)$ in the mid-period. This confirms the energy-saving effect for an office building with a high rate of cooling energy consumption.

Next, the peak heating and cooling energy consumptions were analyzed by window model. The results are summarized in Table 6 and Figure 12. Those days on which energy consumption peaked were confirmed as for cooling in August 6, and heating in January 29. With the ECW, the peak heating energy consumption decreased by $4.77 \mathrm{kWh} /$ day $(3.26 \%)$ compared to the reference model, while the peak cooling energy consumption was reduced by $47.59 \mathrm{kWh} /$ day $(9.79 \%)$. This reduction in the peak energy consumption will result in both energy cost reductions and an improvement in the level of indoor comfort due to the stabilizing of the building energy consumption. 
Table 6. Peak heating and cooling day energy consumption.

\begin{tabular}{ccc}
\hline \multirow{2}{*}{ Type } & \multicolumn{2}{c}{ Amount of Energy [kWh/day] } \\
\cline { 2 - 3 } & Heating (January 29) & Cooling (August 6) \\
\hline C-1 & 135.17 & 478.83 \\
C-2 & 134.11 & 485.90 \\
C-3 & 133.45 & 469.87 \\
ECWs & 129.34 & 438.32 \\
\hline
\end{tabular}

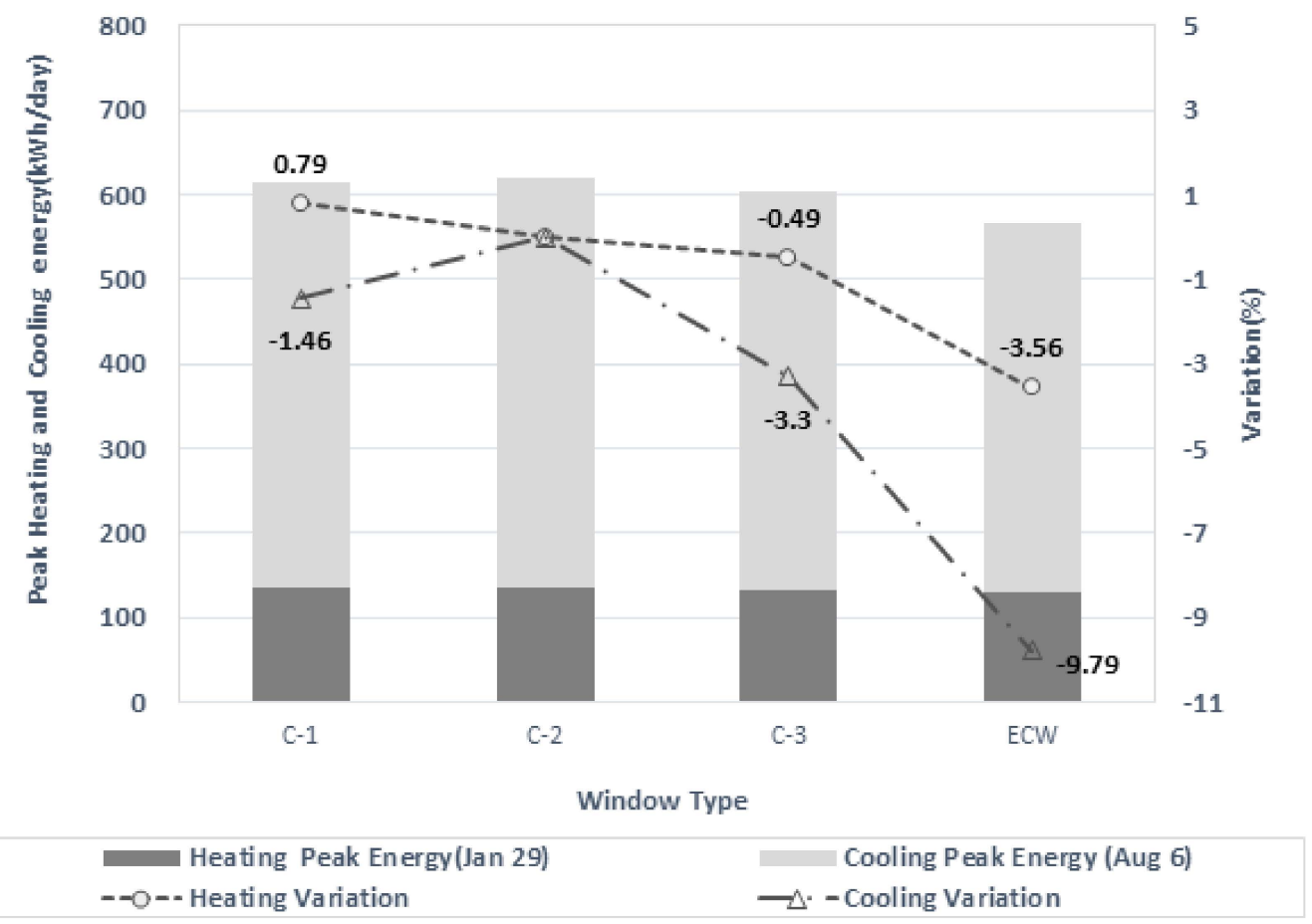

Figure 12. Peak Heating and Cooling energy consumption. (Variation: A percentage change compared to base model(C-2)).

\subsection{Lighting Energy Consumption}

The results of analyzing the effects on lighting energy consumption according to the window type, as indicated by the VLT, are summarized in Table 7. The C-type windows, including the reference model, have identical or similar VLTs, while the ECW exhibits different values depending on whether it is in its colored or bleached state. The VLT of the ECW in the colored state is the lowest, at $0.10 \%$, among all the windows. Based on this value, the annual lighting energy consumption will be highest with the ECW, at $43,350 \mathrm{kWh} / \mathrm{yr}$, an increase of $5500 \mathrm{kWh} / \mathrm{yr}(14.53 \%)$ over the reference model. This is a result of an increase in the indoor lighting usage with the ECWs, as the VLT is lower during the mid-periods and summer, when the ECWs are in their colored state.

Table 7. Lighting energy analysis VLT.

\begin{tabular}{|c|c|c|c|}
\hline \multirow{2}{*}{\multicolumn{2}{|c|}{ Type }} & \multirow{2}{*}{ VLT [\%] } & Amount of Energy [kWh/yr] \\
\hline & & & Lighting \\
\hline \multicolumn{2}{|c|}{ C-1 } & 0.74 & 37,850 \\
\hline \multicolumn{2}{|c|}{$\mathrm{C}-2$} & 0.74 & 37,850 \\
\hline \multicolumn{2}{|c|}{$\mathrm{C}-3$} & 0.71 & 37,850 \\
\hline ECWs & ECB & 0.66 & 43,350 \\
\hline
\end{tabular}


Based on the results listed in Table 5, an integrated analysis of the annual lighting energy and heating/cooling energy consumptions was performed. The use of the C-1 and C-3 types results in a slight increase in the heating energy consumption, although the lighting energy consumption was the same as that with the reference model. With the ECWs, the heating energy consumption decreased by $400 \mathrm{kWh}(0.83 \%)$. With the ECWs, the cooling energy consumption decreased by $10,158 \mathrm{kWh}$ $(13.16 \%)$, although there was an increase in the lighting energy consumption. Even if the lighting energy consumption is integrated with the cooling/heating energy consumption, the use of the ECWs produced a decrease in the energy consumption of $11,207 \mathrm{kWh} / \mathrm{yr}(8.89 \%)$ relative to the reference model, making it the most energy-efficient window in terms of visual comfort performance.

\subsection{Analysis of Energy Cost}

Energy cost analysis was carried out using the annual heating/cooling energy and lighting energy in an integrated manner. The General service (b) (high-voltage (A)II) rate table provided by KEPCO [23] was used for calculating the electric rate which reflects the electric base consumption. Thus, the electric rate was a summation of a basic charge (8320 KRW (\$7.37)) and an actual consuming charge $(109 \mathrm{KRW} / \mathrm{kWh}(\$ 0.10 / \mathrm{kWh}))$. The gas rate was calculated using the rate table provided by Seoul City Gas rate [24]. The gas rate was a summation of $15.7309 \mathrm{KRW} / \mathrm{MJ}$ (\$0.01/MJ) and a $10 \%$ surtax.

The results of energy cost analysis are shown in Table 8. The total annual energy cost of ECWs was $47,400,416 \mathrm{KRW}(\$ 41,984.43)$, which means $805,701 \mathrm{KRW}$ (\$713.64) was saved compared to the reference model. This results indicates that the ECWs are the most economical windows among the four tested windows.

Table 8. Energy cost analysis.

\begin{tabular}{cccc}
\hline \multirow{2}{*}{ Type } & \multicolumn{3}{c}{ Cost of Energy } \\
\cline { 2 - 4 } & Electricity & Gas & Total \\
\hline C-1 & $12,341,670(\$ 10,920.84)$ & $36,135,296(\$ 31,978.31)$ & $48,476,966(\$ 42,899.18)$ \\
C-2 & $12,550,950(\$ 11,106.05)$ & $35,655,167(\$ 31,558.83)$ & $48,206,117(\$ 42,664.88)$ \\
C-3 & $12,116,040(\$ 10,721.21)$ & $36,342,121(\$ 32,166.86)$ & $48,458,161(\$ 42,888.07)$ \\
ECWs & $12,041,048(\$ 10,654.85)$ & $35,359,368(\$ 31,297.02)$ & $47,400,416(\$ 41,951.87)$ \\
\hline
\end{tabular}

\section{Conclusions}

In this present study, the characteristics of ECWs and their relationship to the energy consumption of an office building into which they are incorporated, were analyzed through the application of an e-Quest computer simulation. The results were as follows:

1. Regardless of the window type, the annual solar transmittance varies according to the orientation of the windows, in descending order of south-west-east-north. In all orientation, the solar transmittance was the highest in ECWs in winter compared to the reference model and lowest in summer. The room temperatures according to the solar transmittance, ECWs were highest among all the window types, $19.55^{\circ} \mathrm{C}$ in winter and $31.15^{\circ} \mathrm{C}$ in mid-term, while lowest at $38.38^{\circ} \mathrm{C}$ in summer. These results are expected to be have an excellent effect on reducing cooling and heating energy consumption.

2. The total annual energy consumption, according to window type, was found to decrease in the order of reference model(C-2)-C-1-C-3-ECW. The ECWs was 114,912 kWh/yr, attaining the greatest reduction at $10,578 \mathrm{kWh} / \mathrm{yr}(8.43 \%)$, relative to the reference model. Accordingly, ECWs will provide an energy-saving effect for an office building for which the cooling energy consumption ratio is high. The peak energy consumption days were confirmed to be cooling in August 6, and heating in January 29. As the use of the ECWs realized reductions in both 
heating and cooling energy consumption, their application would result in cost reductions and an improvement in indoor comfort.

3. The ECWs have different VLT values depending whether they are in the colored or bleached state and the VLT value for an ECW in the colored state lowest than any other of the window types. The lighting energy of ECWs was the highest, but, even if the lighting energy consumption is integrated with the cooling/heating energy consumption, the use of ECWs would realize an overall reduction in the energy consumption of $11,207 \mathrm{kWh} / \mathrm{yr}(8.89 \%)$. As such, the ECW is the most energy-efficient window in terms of visual comfort.

An analysis of the solar transmittance, indoor temperature, building energy and lighting energy consumptions with ECWs with different thermal and optical properties was performed. As a result, it was ultimately confirmed that, compared to three types of widely applied low-E glass, an ECW exhibits excellent performance in terms of building energy reduction. As such, this type of window is expected to find many applications in building envelopes.

Given this potential, further comparisons and analyses must be conducted to determine the physical properties of an ECW. In the present study, an ECW performance analysis was undertaken by examining the thermal and optical performances as they would apply to standard-sized office buildings. Moreover, additional performance evaluations and studies of various combinations of physical properties, targeting a more diverse range of buildings, should be undertaken to secure a better and more reliable energy-saving performance for the building envelopes of the future.

Author Contributions: All authors contributed equally. Conceptualization, J.W.M., B.R.P., J.H. and Y.J.C.; methodology, B.R.P., E.J.C. and Y.J.C.; software, B.R.P., E.J.C, Y.J.C., C.L. and J.W.M.; validation, B.R.P., E.J.C, Y.J.C., C.L. and J.W.M.; formal analysis, J.W.M., B.R.P., E.J.C. and Y.J.C.; investigation, B.R.P., E.J.C. and Y.J.C.; resources, B.R.P., J.H., E.J.C. and Y.J.C.; data curation, J.W.M., B.R.P., J.H. and Y.J.C.; writing-original draft preparation, J.W.M., B.R.P., J.H. and Y.J.C.; writing-review and editing, J.W.M., B.R.P., J.H., E.J.C. and Y.J.C.; visualization, B.R.P. and Y.J.C; supervision, J.W.M. and J.H.; project administration, J.W.M. and J.H.; funding acquisition, J.W.M. and J.H.

Funding: This research was supported by the National Research Foundation of Korea (NRF) Grant funded by the Ministry of Science and ICT for First-Mover Program for Accelerating Disruptive Technology Development (NRF-2018M3C1B9088457) and by the Chung-Ang University Research Scholarship Grants in 2018.

Conflicts of Interest: The authors declare no conflict of interest.

\section{References}

1. Thibaut, A.; Brian, D.; John, D. Global Status Report 2017; Global Alliance for Buildings and Construction (GABC): Paris, France, 2017; p. 6. Available online: https://www.worldgbc.org/sites/default/files/UNEP\% 20188_GABC_en\%20\%28web\%29.pdf (accessed on 15 December 2017).

2. Park, D.S. A Study on the Building Energy Performance Evaluation by Solar Heat Gain Coefficient (SHGC) of Low-e Window. Master's Thesis, Hanbat University, Daejeon, Korea, 2008.

3. Gustavsen, A.; Jelle, B.P.; Arasteh, D.; Kogler, C. State-of-the-Art Highly Insulating Window Frames_Research and Market Review; INTEF Building and Infrastructure: Olso, Norway, 2007; p. 6. Available online: https://windows.lbl.gov/publications/state-art-highly-insulating-window-framesresearch-and-market-review (accessed on 2 November 2016).

4. Reilly, S.; Arasteh, D.; Selkowitz, S. Thermal and optical analysis of switchable window glazings. Sol. Energy Mater. 1991, 22, 1-14. [CrossRef]

5. Picclo, A.; Simone, F. Performance requirements for electrochromic smart window. J. Build. Eng. 2015, 3, 94-103. [CrossRef]

6. Rezaei, S.D.; Shannigrahi, S.; Ramakrishna, S. A review of conventional, advanced, and smart glazing technologies and materials for improving indoor environment. Sol. Energy Mater. Sol. Cells 2017, 159, $26-51$. [CrossRef] 
7. Pittaluga, M.; Loddo, G.; Cossu, G.P.; Ludoni, D. Electrochromic glazing in contemporary architecture: Examples of use and opportunities for the future. In Proceedings of the XXXVII IAHS World Congress on Housing, Design, Technology, Refurbishment and Management of Building, Santander, Spain, 26-29 Octorber 2010.

8. Granqvist, C.G. Electrochromics for smart windows: Oxide-based thin films and devices. Thin Solid Film. 2014, 564, 1-38. [CrossRef]

9. Ma, R.; Chen, Y. BIPV-Powered Smart Windows Utilizing Photovoltaic and Electrochromic Devices. Sensors 2012, 12, 359-372. [CrossRef] [PubMed]

10. Lee, E.S.; Tavil, A. Energy and visual comfort performance of electrochromic windows with overhangs. Build. Environ. 2007, 42, 2439-2449. [CrossRef]

11. Dussault, J.; Gosselin, L. Office buildings with electrochromic windows: A sensitivity analysis of design parameters on energy performance, and thermal and visual comfort. Energy Build. 2017, 153, 50-62. [CrossRef]

12. Sbar, N.L.; Podbelski, L.; Yang, H.M.; Pease, B. Electrochromic dynamic windows for office buildings. Inter. J. Sustain. Built Environ. 2012, 1, 125-139. [CrossRef]

13. Fernandes, L.; Lee, E.; Ward, G. Lighting energy savings potential of split-pane electrochromic windows controlled for daylighting with visual comfort. Energy Build. 2013, 61, 8-20. [CrossRef]

14. DeForest, N.; Shehabi, A.; Garcia, G.; Greenblatt, J.; Masanet, E.; Lee, E.S.; Selkowitz, D.J. Milliron, Regional performance targets for transparent near-infrared switching electrochromic window glazings. Build. Environ. 2013, 61, 160-168. [CrossRef]

15. Deb, S.K.; Lee, S.; Tracy, C.E.; Pitts, J.R.; Gregg, B.A.; Branz, H.M. Stand-alone photovoltaic-powered electrochromic smart window. Electrochim. Acta 2001, 46, 2125-2130. [CrossRef]

16. Wang, Y.; Runnerstrom, E.L.; Miliron, D.J. Switchable Materials for Smart Windows. Annu. Rev. Chem. Biomol. Eng. 2016, 7, 283-304. [CrossRef] [PubMed]

17. Niklasson, G.A.; Granqvist, C.G. Electrochromics for smart windows: Thin films of tungsten oxide and nickel oxide, and device based on these. J. Mater. Chem. 2007, 17, 127-156. [CrossRef]

18. Runnerstrom, E.L.; Llotdes, A.; Lounis, S.D.; Milliron, D.J. Nanostructured electrochromic windows tranditional materials and NIR-selective plasmonic nanocrystals. Chem. Commun. 2014, 50, 10555-10572. [CrossRef] [PubMed]

19. Baetens, R.; Jelle, B.P.; Gustavsen, A. Properties, Requirements and Possibilities of Smart Windows for Dynamic Daylight and Solar Energy Control in Buildings: A State-of-the-Art Review. Sol. Mater. Sol. Cells 2010, 94, 87-105. [CrossRef]

20. Oh, M.H.; Tae, S.H. An Applicability Estimation of Electrochromic Glazing in the Office Building based on Analyzing Optical Properties and Heating and Cooling Load. J. Arch. Inst. Korea 2018, 38, 426-429.

21. Sageglass. Available online: http:/ / www.sageglass.com (accessed on 1 March 2014).

22. James, J.H. DOE-2.2 Volume 4: Libraries \& Reports, DOE, California, USA, 2009; pp. 25. Available online: doe2.com/download/doe-22/DOE22Vol4-Libraries_47.pdf (accessed on 1 March 2018).

23. Korea Electric Power Corporation. Available online: http://cyber.kepco.co.kr/ckepco/front/jsp/CY/E/E/ CYEEHP00102.jsp (accessed on 8 May 2018).

24. Seoul City Gas Co., Ktd. Available online: http:/ / www.seoulgas.co.kr/front/payment/gasPayTable.do (accessed on 7 January 2018).

(C) 2019 by the authors. Licensee MDPI, Basel, Switzerland. This article is an open access article distributed under the terms and conditions of the Creative Commons Attribution (CC BY) license (http://creativecommons.org/licenses/by/4.0/). 